\title{
Natural Convection From an Elliptic Tube with Major Axis Vertical and with Uniform Surface Heat Flux
}

\author{
F. M. Mahfouz \\ Mechanical Power Department, Faculty of Engineering, \\ Menoufia University, Egypt.
}

\begin{abstract}
The problem of natural convection from an elliptic tube with its major axis vertical and heated uniformly is investigated. The study is based on the solution of full governing equations without boundary layer simplifications. The study focuses on the effect of the main controlling parameters on both flow and thermal fields. The controlling parameters are the modified Rayleigh number, $\mathrm{Ra}$ Prandtl number, $\mathrm{Pr}$ and axis ratio, Ar. The Ra is considered up to $10^{7}$, the $\operatorname{Pr}$ is considered up to 10 while the axis ratio is varied from 0.05 (almost flat plate) to 0.998 ( almost circular cylinder). Results are presented for the local and average Nusselt numbers and local and mean surface temperatures. The study revealed that as Rayleigh number and/or Prandtl number increase the average Nusselt number increases, resulting in a decrease in mean surface temperature. On the other end, the study showed that the effect of axis ratio on the average Nusselt number is not significant with only smaller decrease in average Nusselt number as the axis ratio increases.
\end{abstract}

Key words Natural convection, Elliptic tube, Axis ratio, Rayleigh number, Prandtl number, Nusselt number.

Manuscript received from Dr . F.M.Mahfouz

Accepted on : $22 / 7 / 2002$

Engineering Research Journal Vol 25, No 4, 2002 Minufiya University, Faculty Of

Engineering, Shebien EI-Kom, Egypt , ISSN 1110-1180 
In natural heat transfer problems the surface thermal boundary conditions are of great importance in determining both flow and thermal fields. The thermal boundary conditions encountered in heat convection problems are in general the prescribed surface temperature and the prescribed surface heat flux. In the case of prescribed surface temperature boundary condition the main interest of research is to calculate the heat transfer rate from/to the surface. While in the case of prescribed heat flux boundary condition the main interest is to inspect the surface temperature distribution. Most of the pervious studies on natural heat convection problems have focused mainly on constant surface temperature boundary conditions. However, the case of uniform surface heating is practically important.

Natural convection from cylindrical tubes has gained considerable attention, for its importance in the number of applications. These applications include cooling of electrical and electronic components, design of solar collectors and heat exchangers and many others. In heat exchanger design, special interest was directed to tubes of elliptic crosssection since they were found to create less resistance to cooling fluid which results in less pumping power. Although in heat exchangers the forced convection is dominant the natural convection becomes the dominant mode of heat transfer in case of power failure. Moreover, elliptical tube geometry has the privilege of being flexible to approach two limiting cases, flat plate and circular cylinder. This privilege enables researchers to verify and to know the range of their results by comparing them with well known previous results for these two limiting cases. In the case of natural convection with prescribed heat flux surface conditions, Koh [1] and Kim, et al. [2] investigated the case of circular cylinder while Sparrow and Gregg [3] and Churchill and Ozoe [4] investigated the case of vertical flat plate.

The number of theoretical and experimental studies on natural convection from elliptic tubes is very few. Lin and Chao [5] investigated the natural convection from twodimensional and axisymmetric isothermal bodies with arbitrary contour. In their study the special cases of circular and elliptic cylinders are considered. The solution had the drawback of its inapplicability in the buoyant plume region since it was based on the solution of boundary layer equations with the buoyancy term replaced by a hypothetical outer stream velocity function. Raithby and Hollands [6] studied the natural convection from elliptic tube with its major axis vertical and with different axis ratio. Both isothermal and constant heat flux boundary conditions are considered with emphasis on isothermal surface cases. In their study, thin layer analysis applicable only to thin boundary layer flow was modified to take into consideration the thick boundary layer effects (resulting at low $\mathrm{Ra}$ ) and turbulent transport (resulting at high $\mathrm{Ra}$ ). Their results for average Nusselt number in the two limiting cases (vertical flat plate and circular cylinder ) were found to be in a good agreement with the experimental data. Merkin [7] solved the governing boundary layer equations for the case of natural convection from elliptic tube with major axis either horizontal or vertical. He presented results for local and averaged heat transfer rates for both constant surface temperature and constant surface heat flux. The obtained results have the same drawback mentioned in [5]. Huang and Mayinger [8] studied experimentally the natural convection from isothermal elliptic tubes with different axis ratios and at different orientations. They reported results for the local and average Nusselt numbers together with a correlation for average Nusselt number.

The analysis of natural convection from isothermal horizontal elliptic tubes and based on the solution of full governing equations were carried out by Badr and Shamsher [9] 
and Badr [10]. Badr and Shamsher [9] considered the case of the tube major axis vertical while Badr [10] considered the case of tube at different orientations. The close scrutiny of: the literature has shown a lack of detailed information on the natural convection from. elliptic tubes with uniform surface heating, which was the motivation to carry out this study. The study is based on the solution of full governing equations without boundary layer assumptions. The buoyancy driven flow is assumed to be laminar and twodimensional. The main controlling variables are the modified Rayleigh number, $\mathrm{Ra}$, the Prandtl number, $\mathrm{Pr}$, and the tube axis ratio (minor to major axis ratio).

\section{Problem Formulation}

Fig. 1 shows the physical model and coordinate system, consisting of horizontal elliptic tube of infinite length placed with its major axis vertical in a quiescent Boussinesq fluid at temperature $T_{\infty}$. The tube surface is suddenly heated with uniform flux $q$ resulting in a buoyancy driven flow. The flow is initially transient but with elapse of time it approaches the steady state. The conservation equations of mass, momentum and energy in terms of the vorticity, stream function and temperature can be written in Cartesian coordinates as

$$
\begin{gathered}
\frac{\partial \zeta^{\prime}}{\partial \tau}+\frac{\partial \psi}{\partial \mathrm{y}^{\prime}} \frac{\partial \zeta^{\prime}}{\partial \mathrm{x}^{\prime}}-\frac{\partial \psi}{\partial \mathrm{x}^{\prime}} \frac{\partial \zeta^{\prime}}{\partial \mathrm{y}^{\prime}}=v \nabla^{2} \zeta^{\prime}+\frac{1}{\rho}\left[\frac{\partial F_{\mathrm{y}^{\prime}}}{\partial x^{\prime}}-\frac{\partial \mathrm{F}_{\mathrm{x}^{\prime}}}{\partial \mathrm{y}^{\prime}}\right] \\
\zeta^{\prime}=-\nabla^{2} \psi^{\prime} \\
\frac{\partial \mathrm{T}}{\partial \tau}+\frac{\partial \psi^{\prime}}{\partial y^{\prime}} \frac{\partial \mathrm{T}}{\partial \mathrm{x}^{\prime}}-\frac{\partial \psi^{\prime}}{\partial \mathrm{x}^{\prime}} \frac{\partial \mathrm{T}}{\partial \mathrm{y}^{\prime}}=\frac{\mathrm{k}}{\rho \mathrm{c}_{\mathrm{v}}} \nabla^{2} T \\
\nabla^{2}=\frac{\partial^{2}}{\partial \mathrm{x}^{\prime 2}}+\frac{\partial^{2}}{\partial \mathrm{y}^{\prime 2}}
\end{gathered}
$$

where

$\tau$ is the time, $p$ is the density, $v$ is the kinematic viscosity, $k$ is the thermal conductivity, $\mathrm{c}_{y}$ is the specific heat. $\zeta^{\prime}$ is the vorticity, $\psi^{\prime}$ is the stream function and $\mathrm{T}$ is the temperature. $F_{x^{\prime}}=\rho g \beta\left(T-T_{\infty}\right)$, and $F_{y^{\prime}}=0$ are the $x^{\prime}, y^{\prime}$ component of the buoyancy force, where $\beta$ is the coefficient of thermal expansion of the fluid.

The boundary conditions are mainly the no-slip and impermeability conditions on the tube surface and the stagnant ambient conditions very far away from it. The boundary condition can be expressed as :

$$
\begin{array}{cc}
\psi^{\prime}=\frac{\partial \psi^{\prime}}{\partial \mathrm{x}^{\prime}}=0, \frac{\partial \psi^{\prime}}{\partial \mathrm{y}^{\prime}}=0, \text { and } \quad q=\text { const. } \quad \text { On the tube surface } \\
\frac{\partial \psi^{\prime}}{\partial \mathrm{x}^{\prime}} \rightarrow 0, \frac{\partial \psi^{\prime}}{\partial \mathrm{y}^{\prime}} \rightarrow 0, \text { and } \mathrm{T} \rightarrow \mathrm{T}_{\infty} \quad \text { far away from the tube surface }
\end{array}
$$

where $q$ is the constant surface heat flux. The following dimensionless variables are now introduced

$$
\mathrm{x}=\frac{x^{\prime}}{a}, \mathrm{y}=\frac{\mathrm{y}^{\prime}}{a}, \mathrm{t}=\frac{\tau \alpha}{a^{2}}, \quad \psi=\frac{\psi^{\prime}}{\alpha} \quad \zeta=-\zeta^{\prime} \frac{a^{2}}{\alpha}, \quad \text { and } \quad \phi=\frac{k\left(T-T_{\infty}\right)}{a q}
$$

where $a$ is the length of semimajor axis and $\alpha$ is the thermal diffusivity of the fluid. In order to obtain accurate numerical solution the dimensionless form of governing equations (1)-(3) are transformed first to the elliptic coordinates $\xi, \eta$ using the following transformation

$$
\xi+i \eta=\cosh ^{-1} \frac{\mathrm{x}+\mathrm{iy}}{\sqrt{1-\mathrm{Ar}^{2}}}
$$


where $\mathrm{Ar}$ is the minor to major axis ratio or tne ellpse and $\eta=v$ cuncspunus is un topmost point on the tube surface as shown in Fig. 1. Using the above transformation, the dimensionless form of governing equations read the following in the elliptic coordinates:

$$
\begin{gathered}
J \frac{\partial \zeta}{\partial \mathrm{t}}=\operatorname{Pr}\left(\frac{\partial^{2} \zeta}{\partial \xi^{2}}+\frac{\partial^{2} \zeta}{\partial \eta^{2}}\right)+\frac{\partial \psi}{\partial \xi} \frac{\partial \zeta}{\partial \eta}-\frac{\partial \psi}{\partial \eta} \frac{\partial \zeta}{\partial \xi} \\
+\frac{R a P r}{8 \varepsilon}\left[\cosh \xi \sin \eta \frac{\partial \phi}{\partial \xi}+\sinh \xi \cos \eta \frac{\partial \phi}{\partial \eta}\right] \\
J \zeta=\frac{\partial^{2} \psi}{\partial \xi^{2}}+\frac{\partial^{2} \psi}{\partial \eta^{2}} \\
J \frac{\partial \phi}{\partial \mathrm{t}}=\left(\frac{\partial^{2} \phi}{\partial \xi^{2}}+\frac{\partial^{2} \phi}{\partial \eta^{2}}\right)+\frac{\partial \psi}{\partial \xi} \frac{\partial \phi}{\partial \eta}-\frac{\partial \psi}{\partial \eta} \frac{\partial \phi}{\partial \xi}
\end{gathered}
$$

where $J=\left(\cosh ^{2} \xi-\cos ^{2} \eta\right)\left(1-A r^{2}\right)$ is the determinant of the Jacobian of transformation matrix, $\operatorname{Ra}=\mathrm{g} \beta(2 a)^{3} a q / \mathrm{kv} \alpha$ is the modified Rayleigh number and $\operatorname{Pr}=v / \alpha$ is the Prandtl number. The velocity components in $\xi$ and $\eta$ directions are then defined as

$$
\mathrm{V}_{\xi}=\frac{1}{J^{1 / 2}} \frac{\partial \psi}{\partial \eta} \quad \text { and } \quad \mathrm{V}_{\mathrm{\eta}}=-\frac{1}{J^{1 / 2}} \frac{\partial \psi}{\partial \xi}
$$

The boundary conditions (4) can now be expressed as

$$
\begin{gathered}
\psi=\frac{\partial \psi}{\partial \xi}=0, \frac{\partial \psi}{\partial \eta}=0, \text { and } \frac{\partial \phi}{\partial \xi}=-J^{1 / 2} \text { at } \xi=\xi_{0} \\
\frac{\partial \psi}{\partial \xi} \rightarrow 0, \frac{\partial \psi}{\partial \eta} \rightarrow 0, \quad \text { and } \phi \rightarrow 0 \text { as } \xi \rightarrow \infty
\end{gathered}
$$

where $\xi_{0}$ defines the ellipse surface $\left(=\tanh ^{-1} A r\right)$

The temperature of the stagnant fluid around the tube at times $t<0$ is $T_{\infty}(\phi=0)$ which is the same as that of the tube surface. At the start of computations $(t=0)$ the tube surface is heated uniformly with a constant heat flux $q$ and from that moment the time development of both flow and thermal fields starts.

\section{The Method of Solution}

The method used for solving the governing equations (5)-(7) to obtain the time development of both velocity and temperature fields is based on approximating the stream function, vorticity and Temperature using Fourier series expansion. The approach is similar to that used by Collins and Dennis [11] and Badr and Dennis [12]. The stream function $\psi$, vorticity $\zeta$ and temperature $\phi$ are now approximated as

$$
\begin{aligned}
\psi & =\sum_{n=1}^{N} f_{n} \sin (n \eta) \quad n=1,2,, N \\
\zeta & =\sum_{n=1}^{N} g_{n} \sin (n \eta) \\
\phi & =H_{0}+\sum_{n=1}^{N} H_{n} \cos (n \eta)
\end{aligned}
$$

where $N$ is the number of terms in the Fourier series. The functions $f_{n}, g_{n}, H_{0}$ and $H_{n}$ are Fourier coefficients and all are dependent on $\xi$ and $t$. Substitution of equations (9a) $-(9 c)$ in equations (5)-(7) results in the following set of differential equations: 


$$
\begin{aligned}
& \begin{aligned}
& \frac{\partial^{2} f_{n}}{\partial \xi^{2}}-n^{2} f_{n}=\frac{1}{2 \varepsilon^{2}}\left(\cosh 2 \xi g_{n}-\frac{1}{2}\left[g_{(n+2)}\right.\right.\left.\left.+\operatorname{sgn}(n-2) g_{\mid n-21]}\right]\right) \\
& \cosh 2 \xi \frac{\partial g_{n}}{\partial t}-\frac{1}{2}\left[\frac{\partial g_{(n+2)}}{\partial t}+\operatorname{sgn}(n-2) \frac{\partial g_{[n-2]}}{\partial t}\right] \\
& \quad=2 \varepsilon^{2} \operatorname{Pr}\left(\frac{\partial^{2} g_{n}}{\partial \xi^{2}}-n^{2} g_{n}\right)+S_{n} \\
& \cosh 2 \xi \frac{\partial}{\partial t}\left(\begin{array}{l}
H_{0} \\
H_{n}
\end{array}\right)-\frac{1}{2} \frac{\partial}{\partial t}\left[\begin{array}{c}
H_{2} \\
H_{(n+2)}
\end{array}\right]+\frac{1}{2} \frac{\partial}{\partial t}\left[\begin{array}{c}
0 \\
H_{[n+2]}
\end{array}\right] \\
&=2 \varepsilon^{2} \frac{\partial^{2}}{\partial \xi^{2}}\left(\begin{array}{l}
H_{0} \\
H_{n}
\end{array}\right)-2 n^{2} \varepsilon^{2}\left(\begin{array}{l}
0 \\
H_{n}
\end{array}\right)+\left(\begin{array}{l}
Z_{0} \\
Z_{n}
\end{array}\right)
\end{aligned}
\end{aligned}
$$

where

$$
\operatorname{sgn}(n-2) \text { means the sign of term }(n-2) \text { and } \operatorname{sgn}(n-2)=g_{|n-2|}=0, H_{|n-2|}=H_{0} \text { for } n=2 \text {. }
$$

The terms $S_{n}, Z_{0}$ and $Z_{n}$ are all easily identifiable functions of $\xi$ and $t$.

The boundary conditions for all the functions presented in equations (10)-(12) are obtained from equations (8) and can be expressed as

$$
\begin{aligned}
& \mathrm{f}_{\mathrm{n}}=\frac{\partial \mathrm{f}_{\mathrm{n}}}{\partial \xi}=0, \text { and } \frac{\partial \mathrm{H}_{0}}{2 \partial \xi}+\sum_{\mathrm{l}}^{\mathrm{N}} \frac{\partial \mathrm{H}_{\mathrm{n}}}{\partial \xi} \cos (\mathrm{n \eta})=-J^{1 / 2} \text { at } \xi=\xi_{0} \\
& \frac{1}{J^{1 / 2}} \frac{\partial \mathrm{f}_{\mathrm{n}}}{\partial \eta}, \frac{1}{J^{1 / 2}} \frac{\partial \mathrm{f}_{\mathrm{n}}}{\partial \xi}, \mathrm{g}_{\mathrm{n}}, \mathrm{H}_{0}, \mathrm{H}_{\mathrm{n}} \rightarrow 0 \quad \text { as } \xi \rightarrow \infty
\end{aligned}
$$

Integrating the both sides of equation (10) with respect to $\xi$ (after multiplying by $\mathrm{e}^{-\mathrm{n} \xi}$ ). from $\xi=\xi_{0}$ to $\xi=\infty$ and using the boundary conditions (13) one obtains the integral condition :

$$
\int_{\infty}^{\infty} e^{-n \xi}\left(\cosh 2 \xi g_{n}-\frac{1}{2}\left[g_{(n+2)}+\operatorname{sgn}(n-2) g_{\{n-2]}\right]\right) d \xi=0 .
$$

The above integral condition is used to get the values of the function $g_{n}$ on the tube surface to get the surface vorticity distribution.

The number of points used in the $\xi$ direction is 200 with a grid size taken as 0.05 . This approximates the outer boundary at infinity at $\xi_{\max }=\xi_{0}+10$, which corresponds to a very large distance from the tube surface. Such large distance is necessary to ensure that the conditions at infinity are appropriately incorporated in the numerical solution. However, the grid size is reduced to 0.025 for higher values of Rayleigh number cases $\left(\mathrm{Ra} \geq 10^{5}\right)$ since at high values of $\mathrm{Ra}$ the velocity gradient near the wall becomes steeper. The logarithmic nature of the $\xi$ coordinate enables us to have equal space steps in the numerical treatment while the physical space steps are gradually growing from very small space steps near the surface to large ones far away. This matches quite well the physical situation where steep variations near the surface exist. The number of terms in the Fourier series is taken as 5 terms at the start and then more terms are added as the time elapses until reaching the steady state. The maximum number of terms $N$ used in most of the cases considered was 40 . The solution procedure is the same as that described by Mahfouz and Badr [13]. The only difference is the appearing of the unknown terms $g_{(n+2)}$ 


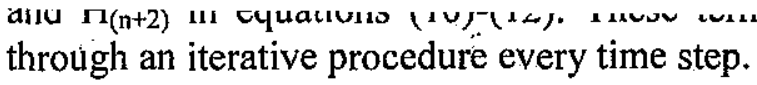

The differential equations (10)- (12) and the boundary and integral conditions (equations (13) and (14) ) are different from those obtained by Badr and Dennis [12]. However, the numerical technique is almost the same and will not be repeated again. Knowing both velocity and temperature fields, the local and average Nusselt numbers as well as the mean surface temperature can be obtained. The local Nusselt number is defined as :

$$
\mathrm{Nu}=2 a h / \mathrm{k}
$$

where $h$ is the local heat transfer coefficient defined as

$$
\mathrm{h}=q /\left(\mathrm{T}_{\mathrm{s}}-\mathrm{T}_{\infty}\right)
$$

From the above definitions one can deduce the relation between the $\mathrm{Nu}$ and Fourier coefficients $\mathrm{H}_{0}$ and $\mathrm{H}_{n}$ as:

$$
\mathrm{Nu}=\frac{4}{\mathrm{H}_{\mathrm{o}}+2 \sum_{l}^{N} H_{n} \cos (\mathrm{n} \eta)}
$$

The average Nusselt number can be deduced from the relation :

$$
\overline{\mathrm{Nu}}=2 / \phi_{\mathrm{m}}
$$

where $\phi_{\mathrm{m}}$ is the average surface temperature defined as

$$
\phi_{m}=\frac{2}{\mathrm{p}} \int^{2 \pi}\left(\mathrm{H}_{\mathrm{o}}+2 \sum_{l}^{N} H_{n} \cos (\mathrm{n} \eta) J^{1 / 2} d \eta\right.
$$

where $P$ is the ellipse perimeter.

\section{Results and discussion}

The governing equations along with the boundary conditions were solved in order to get the details of both flow and thermal fields. The Rayleigh number $\mathrm{Ra}$, is considered within its laminar range up to $10^{7}$, the Prandtl number, $\mathrm{Pr}$ is considered up to 10 while the axis ratio, $\mathrm{Ar}$, is considered in the range from almost zero (flat plate) to almost one (circular cylinder). The accuracy of the method of solution is first verified by comparing the present results with the most available results in the literature. Fig. 2 shows the present results for the average Nusselt number at different Rayleigh number and at $\mathrm{Pr}=1$ for both flat plate and circular cylinder in the case of constant heat flux surface condition. Shown in the same figure are the correlation for $\vec{N}_{4}$ presented in Ref. [6] ( Eq. 33 and Table 6) in the case of flat plate and circular cylinder. The comparison shows very good agreement with maximum difference less than $4 \%$ at all points.

Fig. 3 shows the surface temperature distribution in case of $\mathrm{Ar}=0.5, \mathrm{Pr}=1$ and at different Ra together with those based on the boundary layer solution obtained by Merkin [7]. The boundary layer results may be the limiting case as $\mathrm{Ra} \rightarrow \infty$ for laminar flow excluding the plume region. At Rayleigh number, $\mathrm{Ra}=10^{3}$ the solution based on the boundary layer assumptions deviates significantly from the present solution with $46 \%$ difference between the two solutions at the lower stagnation point $(\eta=180)$. However, as $\mathrm{Ra}$ increases the difference between the two solutions decreases at all points, reaching to $20 \%$ at $\mathrm{Ra}=10^{5}$ (at $\eta=180$ ) and to $14 \%$ at $\mathrm{Ra}=10^{7}$ (at $\eta=0$ ). The surface temperature distribution at Rayleigh number, $\mathrm{Ra}=10^{7}, \mathrm{Pr}=1$ and at different axis ratio is shown in Fig.4. Plotted in the same figure are the boundary layer solutions of Merkin [7]. At such relatively high $\mathrm{Ra}$ the agreement between the two solutions is quite good at all points except in the plume region. In that region a thick thermal boundary layer is formed and boundary layer 
assumptions lead to inaccurate solution. In the plume region, the figure shows that the difference between the two solutions decreases as the ellipse becomes thinner (i.e. Ar decreases). The figure shows a difference of $20 \%$ at $\mathrm{Ar}=0.75,14 \%$ at $\mathrm{Ar}=0.5$ and $7 \%$ at $A \Gamma=0.25$.

Fig. 5 show the time variation of the average Nusselt number for the case of Rayleigh number, $\mathrm{Ra}=10^{4}, \mathrm{Ar}=0.5$ and at three values of Pr. The figure clearly shows that the general variation of Nusselt number is similar to that for isothermal elliptic and circular cylinder ( see Badr [10], Mahfouz and Badr [14]). That is immediately after the tube surface is heated the thermal boundary layer is very thin leading to higher values of $\overline{N u}$. In this early time stages the conduction mode of heat transfer prevails and a quick decrease in $\overline{N u}$ can be observed as a result of growing thermal boundary layer. The decrease in $\overline{N u}$ continues until it reaches a minimum value at a certain time. Beyond this time the buoyancy force develops intensively, causing the fluid to set in intensive motion and hence transition to the convection mode domination. The transition from conduction mode domination to convection mode domination takes the form of overshoot in $\overline{\mathrm{Nu}}$. At later times the buoyancy force effect dominates and the $\overline{N u}$ gradually approaches the steady state value. Fig. 6 shows the time variation of average surface temperature $\phi_{m}$ for the above case. Since the tube surface heat flux is constant the average heat transfer coefficient and the average surface temperature are inversely related as can be inferred from eq. (17). That is as the average heat transfer coefficient increases (or $\overline{N u}$ ) the surface average temperature gets smaller. It can be also seen that as the Pr increases the steady state average temperature decreases as a result of increasing average heat transfer coefficient as shown in Fig. 5.

Table 1 shows the effect of Rayleigh number, Rá Prandtl number, Pr and axis ratio, Ar on the steady state average Nusselt number, $\overline{N u}$. It can be seen that the effect of Ra on steady state $\overline{N u}$ is quite clear, that is at any fixed value of Pr and Ar as Ra increases the $\overline{N u}$ increases. This is quite expected since increasing of $\mathrm{Ra}$ leads to increasing of convection currents intensity and so increasing the average heat transfer coefficient. Also, it can be seen that as the $\operatorname{Pr}$ increases at any fixed value of $\mathrm{Ra}$ the $\overline{N u}$ increases. The table also shows that the effect of axis ratio on the $\overline{N u}$ is not significant with only a slight decrease in $\overline{N u}$ as Ar increases.

The steady local Nusselt Number distribution over the elliptic tube surface for the case of $\mathrm{Ra}=10^{4}, \mathrm{Pr}=1$ and at different axis ratio is shown in Fig. 7. The figure shows that $\mathrm{Nu}$ reaches its maximum value at the lower stagnation point $(\eta=180)$ and then decreases to attain a minimum value. This minimum value occurs at the rear stagnation point for $\mathrm{Ar}>$ 0.5 while it occurs in between $\eta=45$ and $\eta=100$ for $\mathrm{Ar}<0.5$. The figure also shows that changing Ar has a little effect on Nu between $\eta=45$ and $\eta=100$. On the other side, the figure shows that the $\mathrm{Nu}$ values at all points for lower values of $\mathrm{Ar}$ are generally higher than those for higher Ar which explains increasing, though slightly, of $\overline{\mathrm{Nu}}$ as the Ar decreases as shown in Table 1. The surface temperature distribution, $\phi_{\mathrm{s}}$ for the same case is shown in Fig. 8. The figure clearly shows that $\phi_{s}$ is inversely related to $\mathrm{Nu}$ ( shown in Fig. 7). Therefore, the surface temperature assumes its minimum value at the point of maximum heat transfer coefficient $(i, e$, maximum $\mathrm{Nu}$ ) and assumes it maximum temperature at the minimum $\mathrm{Nu}$. Also, it can be inferred from the figure that as $\mathrm{Ar}$ decreases the steady mean surface temperature decreases. 


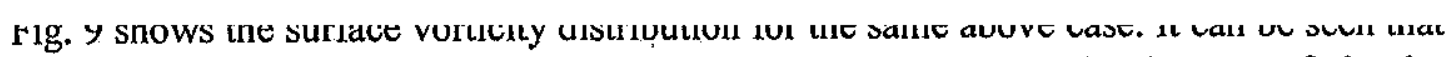
the maximum absolute surface vorticity occurs almost at $\eta=76$. for the case of circular cylinder $(\mathrm{Ar}=0.998)$. As the tube gets thinner (i.e. Ar decreases) the maximum vorticity peak point moves downstream toward the rear stagnation point while another but smaller peak near the forward stagnation point starts appearing. This second peak clearly pronounced at $\mathrm{Ar}=0.25$ and becomes fairly significant as the ellipse approaches the flat plate geometry at $\mathrm{Ar}=0.05$.

Fig: 10 shows the steady state temperature decay along the extension of ellipse major axis $(\eta=0)$ and minor axis $\left((\eta=90)\right.$ for the case of $\operatorname{Ra}=10^{4}, \mathrm{Ar}=0.5$ and at different values of Pr. At the same value of $\operatorname{Pr}$ the figure shows that the temperature gradient at the tube surface $Y^{*}=0$ at the two surface locations $(\eta=0, \eta=90)$ is the same, confirming the fact that the heat flux is constant. Also, the figure shows that as $\operatorname{Pr}$ increases the temperature at the tube surface decreases as a result of increasing heat transfer coefficient. Moreover, the figure shows a slow temperature decay within the plume region along the major axis $(\eta=0)$ while that decay along the minor axis $(\eta=90)$ is much faster, delineating a thinner thermal boundary layer along $(\eta=90)$. However, as Pr increases the thermal boundary layer becomes thinner resulting in much faster temperature decay along $(\eta=90)$.

Fig. 11 Shows the effect of Pr on both flow and thermal fields for the case of $\mathrm{Ra}=10^{4}$, $\mathrm{Ar}=0.5$. Since these fields are symmetrical about the vertical axis, only one half of each field is considered. The flow field is represented by the streamlines while the thermal field is represented by the isotherms. These fields are plotted at time $(t=1)$ at which the thermal field in the vicinity of the tube surface almost reaches its steady state. The figure shows that the effect of Pr on both flow and thermal fields is quite clear, that is at higher values of $\operatorname{Pr}$ the thermal boundary layer gets thinner while the flow field develops faster toward the state ( see figures 5,6) at which the average temperature (or $\overline{\mathrm{Nu}}$ ) attains its steady value. Fig. 12 Show the effect of Ar on both flow and thermal fields for the case of $\mathrm{Ra}=10^{5}, \mathrm{Pr}=0.1$. The figure shows that the axis ratio has a little effect on the streamlines and isotherms. The only effect, though not clear in the figure, is that as the ellipse gets thinner the flow resistance decreases allowing higher approaching flow velocities which results in an increase in $\overline{N u}$ as indicated in Table 1.

\section{Conclusions}

The problem of natural convection from an elliptic tube with its major axis vertical and heated uniformly is investigated. The full governing equations of flow and energy are solved to give the details of both velocity and temperature fields. The effect of modified Rayleigh number, Prandtl number and axis ratio are considered in this study. The value of Rayleigh number is considered up to $10^{7}$, Prandtl number is considerd up to 10 while the axis ratio is varied from 0.05 ( almost flat plate) to 0.998 (almost circular cylinder). Results are presented for the local and average Nusselt numbers. Also the study included the effect of controlling parameters on both local and mean surface temperature. The study showed that as Rayleigh number increases (for a certain fluid and ellipse geometry) the average Nusselt number increases. Also, the study showed that as Prandtl number increases the average Nuselt number increases, resulting in a decrease in mean surface temperature while the effect of axis ratio is not significant with only smaller decrease in mean surface temperature as the axis ratio decreases. 


\section{Nomenclature}

$\begin{array}{ll}a & \text { length of semi-major axis } \\ \mathrm{Ar} & \text { axis ratio }(=\mathrm{b} / \mathrm{a}) \\ \mathrm{b} & \text { length of semi-minor axis } \\ \mathrm{c}^{\prime} & \text { the ellipse eccentricity } \\ \mathrm{f}_{\mathfrak{n}} & \text { Fourier coefficients } \\ \mathrm{g} & \text { gravitational acceleration } \\ \mathrm{g}_{\mathfrak{n}} & \text { Fourier coefficients } \\ \mathrm{h}, \overline{\mathrm{h}} & \text { local and average heat transfer coefficients } \\ \mathrm{H}_{\mathrm{o}}, \mathrm{H}_{\mathrm{n}} & \text { Fourier coefficients } \\ \mathrm{k} & \text { thermal conductivity }\end{array}$

$\mathrm{Nu}, \overrightarrow{\mathrm{Nu}} \quad$ local and average Nusselt numbers

$\operatorname{Pr} \quad$ Prandtl number $(\nu / \alpha)$

q constant heat flux

$R a \quad$ modified Rayleigh number $\left(\mathrm{g} \beta(2 a)^{3} a q / k v \alpha\right)$

$\mathrm{t}$ dimensionless time

T temperature

$\mathrm{Y}^{*} \quad$ the dimensionless distance from the tube surface

\section{Greek symbols}

$\left(=\frac{\mathrm{x}^{\prime}-a}{2 a} \mathrm{Ra}^{0.25}\right)$ along $\eta=0$ and $\left(=\frac{\mathrm{y}^{\prime}-b}{2 a} \mathrm{Ra}^{0.25}\right)$ along line $\eta=90$

$\alpha$

$\beta$

$\phi$

$\varepsilon$

$\eta, \xi$

$\mu$

$v$

$\rho$

$\tau$

$\psi^{\prime}, \psi$

$\zeta^{\prime}, \zeta$

thermal diffusivity

coefficient of thermal expansion

dimensionless temperature $k\left(\mathrm{~T}-\mathrm{T}_{\infty}\right) / a q$

dimensionless ratio, $a / \mathrm{c}^{\prime}$

elliptical coordinates

dynamic viscosity.

kinematics viscosity

density

time

stream function and dimensionless stream functions

vorticity and dimensionless vorticity

\section{Subscripts}

$\mathrm{s}, \mathrm{O}$

at tube surface

$\infty$

at infinite distance from the surface 
I able 1. Errect or Kayleign number, Ka, rranatl number, Irr and Axis ratio, Ar on tne average Nusselt number $\overline{N u}$.

\begin{tabular}{|c|c|c|c|c|}
\hline & & \multicolumn{3}{|c|}{$\overline{N u}$} \\
\hline Ar & $\mathbf{P r}$ & $\mathrm{Ra}=10^{3}$ & $\mathrm{Ra}=10^{4}$ & $\mathrm{Ra}=10^{5}$ \\
\hline \multirow{3}{*}{0.25} & 0.1 & 2.858 & 4.206 & 6.131 \\
\hline & 1 & 3.496 & 5.151 & 7.705 \\
\hline & 10 & 3.921 & 5.784 & 8.624 \\
\hline \multirow{3}{*}{0.5} & 0.1 & 2.805 & 4.081 & 5.911 \\
\hline & 1 & 3.405 & 5.005 & 7.430 \\
\hline & 10 & 3.816 & 5.641 & 8.341 \\
\hline \multirow{3}{*}{0.75} & 0.1 & 2.647 & 3.824 & 5.629 \\
\hline & 1 & 3.231 & 4.715 & 6.981 \\
\hline & 10 & 3.606 & 5.301 & 7.902 \\
\hline
\end{tabular}

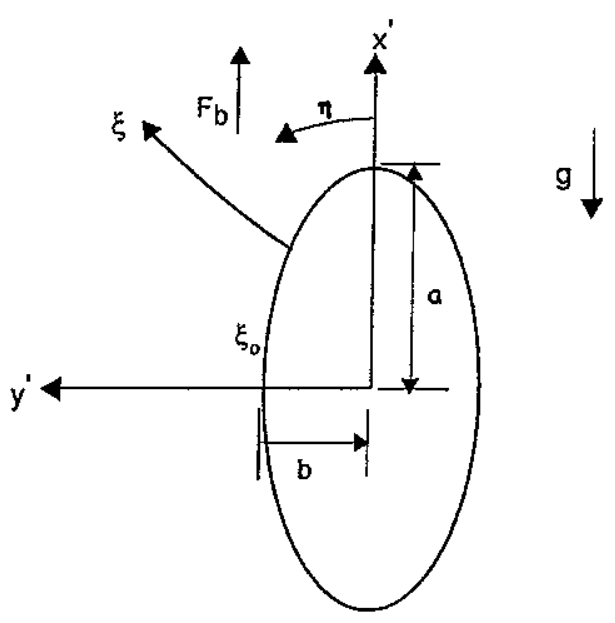

Fig. 1 Physical model and coordinate system

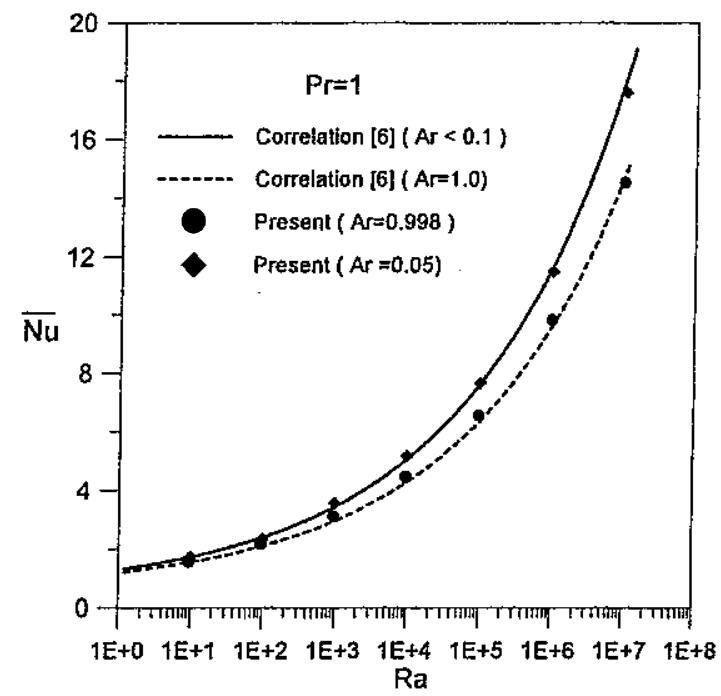

Fig. 2 variation of average Nusselt number with Rayleigh number and comparison with the correlation from [6] for the cases of ( ----) circular cylinder and (__ ) flat plate. 


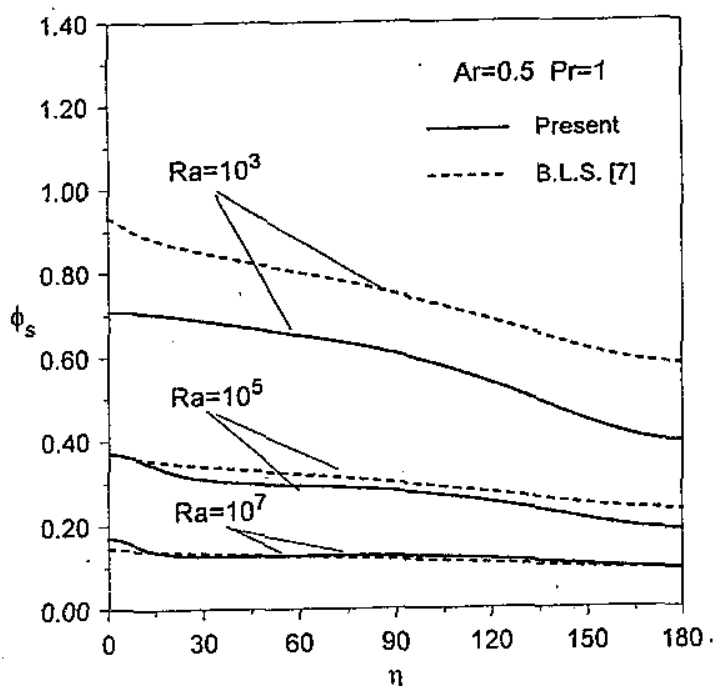

Fig. 3 The temperature distribution along the ellipse surface and comparison with the boundary layer solution ( B.L.S ) obtained from [7] for the case of $A r=0.5$ $\mathrm{Pr}=1$ and at different Rayleigh numbers

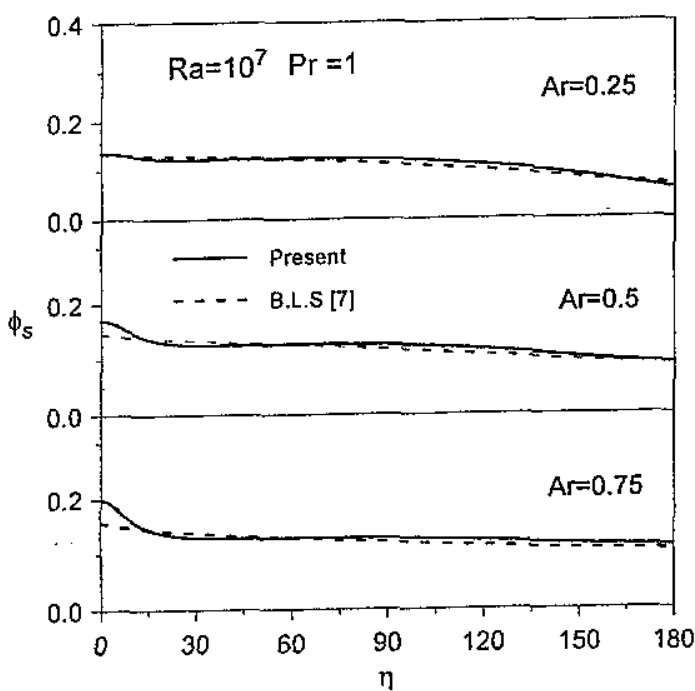

Fig. 4 The temperature distribution along the ellipse surface and comparison with the boundary layer solution ( B.L.S ) obtained from [7] for the case of $\mathrm{Ra}=10^{7}$, $\mathrm{Pr}=1$ and at different axis ratios, Ar.

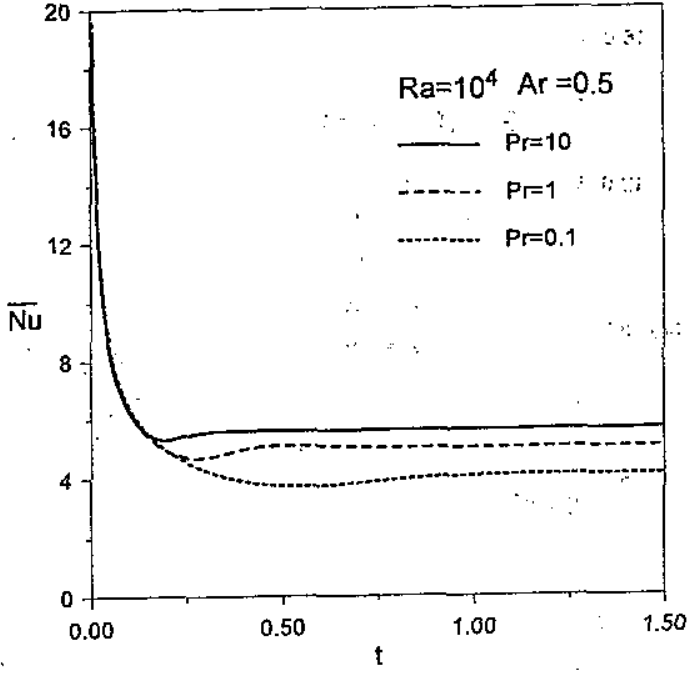

Fig. 5 The time variation of average Nusselt number for the case of $R a=10^{4}$, $A r=0.5$ and at different values of Prandtl Number, Pr.

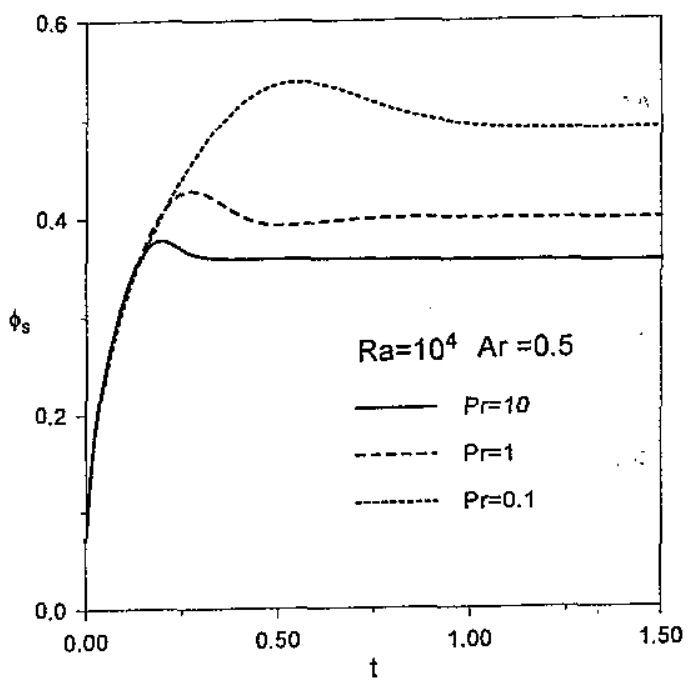

Fig. 6 The time variation of average surface temperature for the case of $\mathrm{Ra}=10^{4}, \quad \mathrm{Ar}=0.5$ and at different values of Prandtl Number, Pr. 


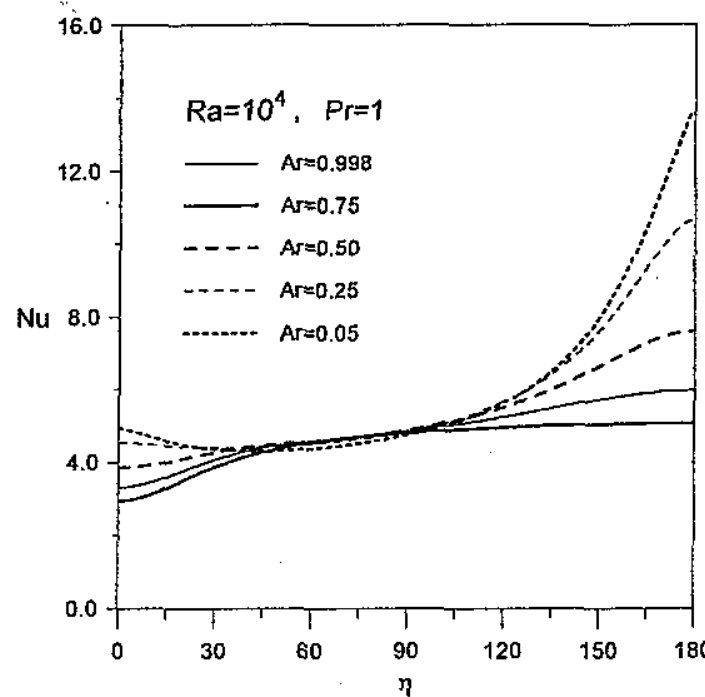

Fig. 7 The local Nusselt number distribution along the ellipse surface for the case of $\mathrm{Ra}=10^{4}, \operatorname{Pr}=1$ and at different axis ratios, Ar.

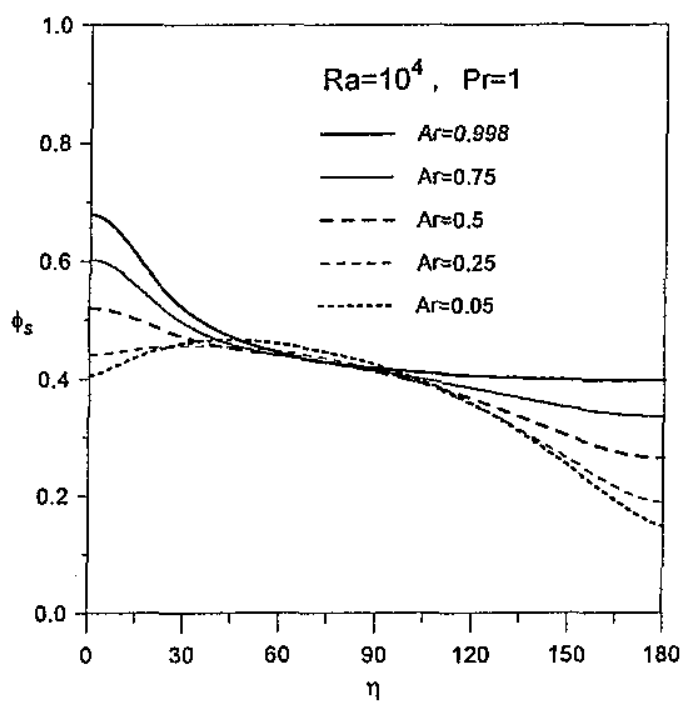

Fig. 8 The temperature distribution along the ellipse surface for the case of $R a=10^{4}$, $\mathrm{Pr}=1$ and at different axis ratios, Ar.

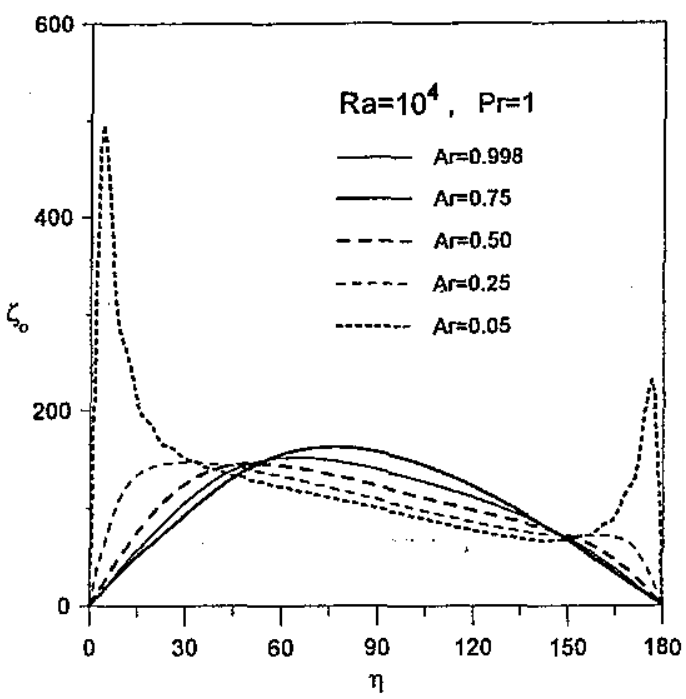

Fig. 9 The surface vorticity distribution for the case of $\mathrm{Ra}=10^{4}, \quad \mathrm{Pr}=1$ and at different axis ratios, Ar.

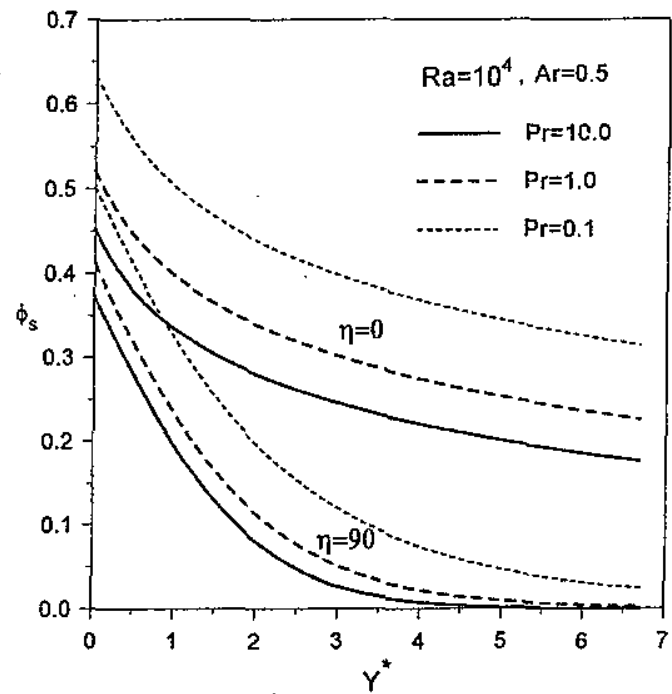

Fig. 10 The temperature distribution along the major axis $(\eta=0)$ and along the minor axis $(\eta=90)$ for the case of $\mathrm{Ra}=10^{4}, \quad \mathrm{Ar}=0.5$ and at different $\mathrm{Pr}$ numbers 
a)

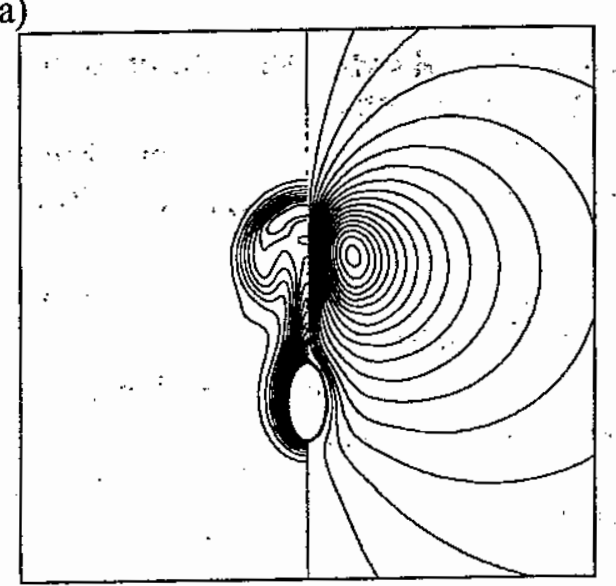

b)

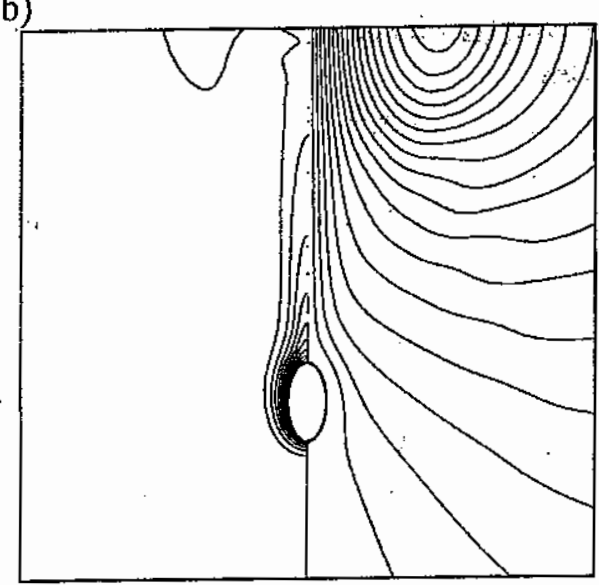

c)

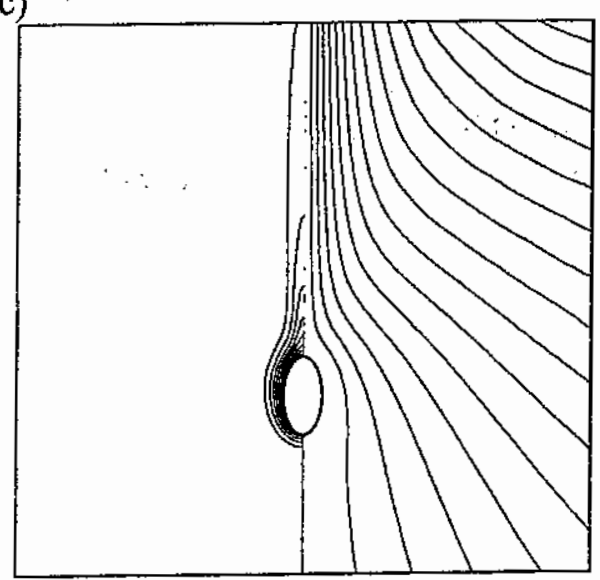

Fig. 11 The streamlines (right) and the isotherms (left) at time $t=1$ for the case of $\mathrm{Ra}=10^{4}, \mathrm{Ar}=0.5$; a) $\left.\operatorname{Pr}=0.1, \mathrm{~b}\right) \operatorname{Pr}=1$ and c) $\mathrm{Pr}=10$

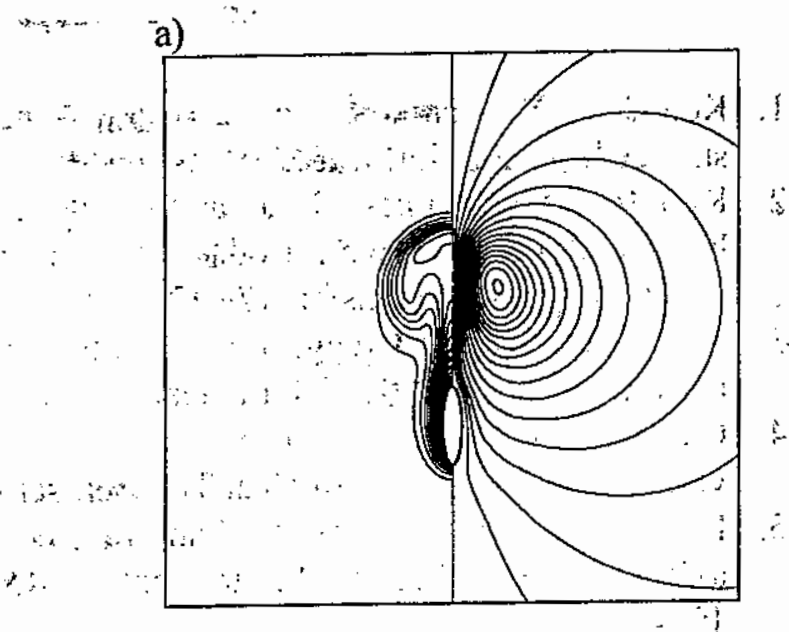

b)

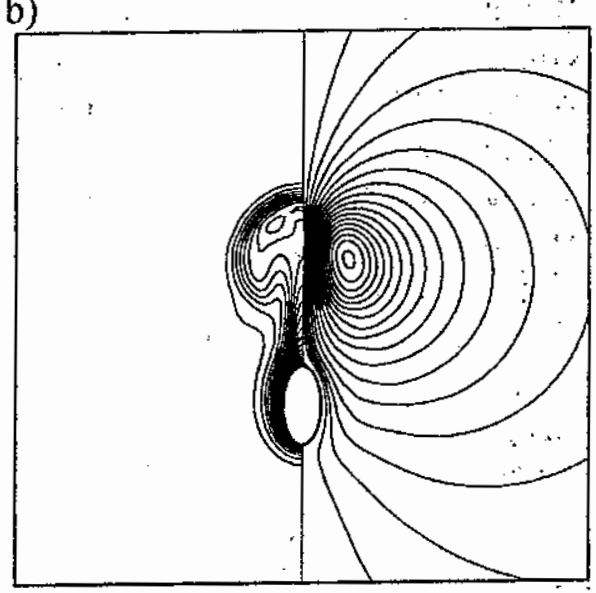

c)

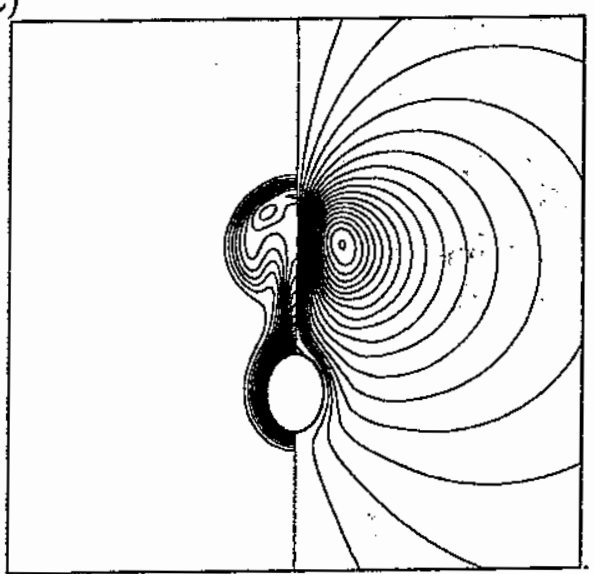

Fig. 12 The streamlines (right) and the isotherms (left) at time $t=0.4$ for the case of $\mathrm{Ra}=10^{5}, \operatorname{Pr}=0.1$, and a) $\mathrm{Ar}=0.25, \mathrm{~b}$ ) $\mathrm{Ar}=0.5$ and c) $\mathrm{Ar}=0.75$ 
1. Koh, J. C. Y., Laminar free convection from a horizontal cylinder with prescribed surface heat flux, Int. J. Heat Mass Transfer, 7, 351-354, 1964.

2. Kim, C. B., Pontlkes, T. J. and Wollershiem, D. E., Free convection from a horizontal cylinder with isothermal and constant heat flux surface conditions, ASME J. of Heat Transfer, 97, 129-130, 1975.

3. Sparrow, E. M. and Gregg, J. L., Laminar free convection from a vertical plate with uniform heat flux, ASME J. of Heat Transfer, 75, 435-440, 1956.

4. Churchill, S. W., and Ozoe, H., A correlation for laminar free convection from a vertical plate, ASME J. of Heat Transfer, series C 95, 540-541, 1973.

5. Lin , F. N. and Chao, B. T., Laminar free convection over two dimensional and axisymmetric bodies of arbitrary contour, ASME J. of Heat Transfer, 96, 435-442, 1974.

6. Raithby, G. D. and Hollands, K.G.T., Laminar and turbulent free convection from elliptic cylinders with a vertical plate and horizontal circular cylinder as special cases, ASME J. of Heat Transfer, 98, 72-80, 1976.

7. Merkin, J. H., Free convection boundary layers on cylinders of elliptic cross section, ASME J. of Heat Transfer, 99, 453-457, 1977.

8. Huang, S.Y. and Mayinger, F., Heat Transfer with natural convection around elliptic tubes, Wärme- und Stoffübertragung, 18, 175-183, 1984.

9. Badr, H. M. and Shamsher K., Free convection from an elliptic cylinder with major axis vertical, Int. J Heat mass Transfer, 36(14), 3593-3602, 1993.

10. Badr, H. M., Laminar natural convection from an elliptic tube with different orientations. ASME J. of Heat Transfer, 119, 709-718, 1997.

11. Collins, W. M. and Dennis, S. C. R., Flow past an impulsively started circular cylinder, J. Fluid Mechanics, 60, 105-127, 1973.

12. Badr, H. M. and Dennis, S. C. R., Time-dependent viscous flow past an impulsively started rotating and translating circular cylinder, J. Fluid Mechanics, 158, 447-488, 1985.

13. Mahfouz, F. M. and Badr, H. M., Flow structure in the wake of a rotationally oscillating cylinder. ASME J. Fluids Engineering, 122, 290-301, 2000.

14. Mahfouz, F. M. and Badr, H. M., Heat convection from a horizontal cylinder performing steady or oscillatory rotary motion, part I steady rotation, Heat and Mass Transfer, 34, 365-373, 1999. 


\section{انقال الحرارة بالحمل الطبيعي من انبوب بيضاوي محوره الاكبر راسي والتسخين الحراري موزع علي سطحه بانظظام}

\section{دم/م/ فتحي محمد محفوظ}

قسم هندسة القوي الميكانيكية-كلية المندسة - جامعة المنوفية- جمهورية مصرر العربية

المخلاصة

في هذا البحث تم دراسة الخمل الطبيعي من أنبوب بيضاوي محوره الاكبر راسي وسطحه يتم تسخينه

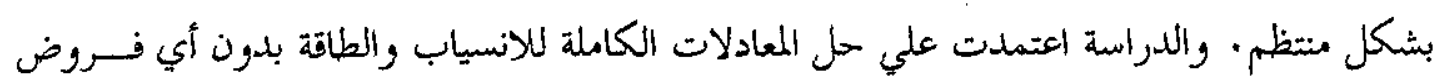

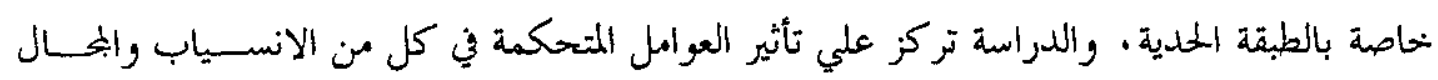

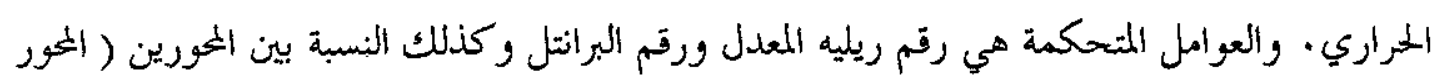

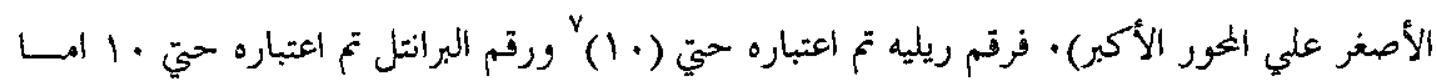

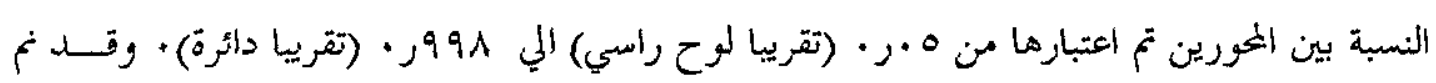

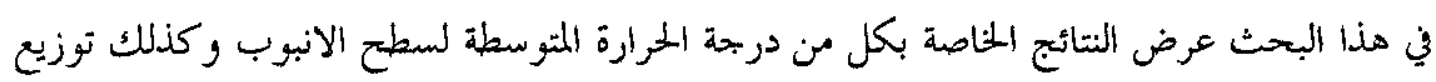

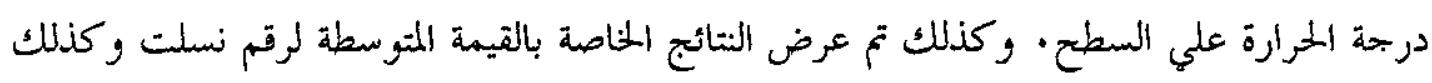

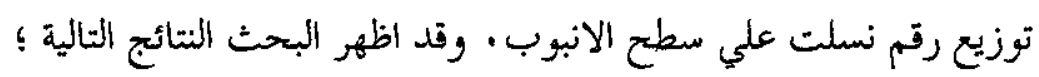

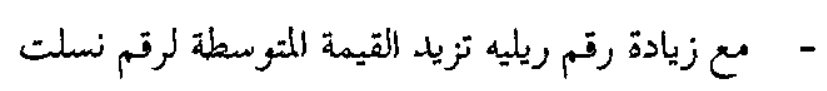

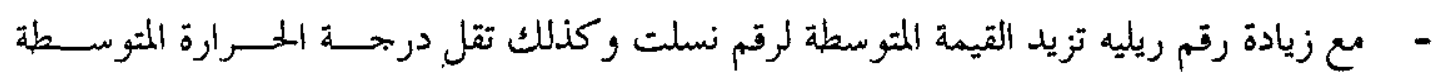
لسطح الانبوب

- مع زيادة النسبة بين المحورين تقل ولكن بشكل طفيف القيمة المتوسطة لرقم نسلت وتزيد درجة

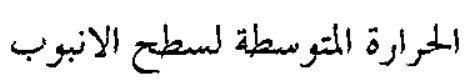

